\title{
A Broadened Scope for the Use of Hydrazones as Neutral Nucleophiles in the Presence of H-Bonding Organocatalysts
}

\author{
Daniel Pettersen, ${ }^{* a}$ Raquel P. Herrera, ${ }^{* a}$ Luca Bernardi, ${ }^{a}$ Franscesco Fini, ${ }^{a}$ Valentina Sgarzani, ${ }^{a}$ Rosario Fernandez, \\ José M. Lassaletta, ${ }^{\mathrm{c}}$ Alfredo Ricci ${ }^{\mathrm{a}}$ \\ a Dipartimento di Chimica Organica ‘A. Mangini’, Università di Bologna, Viale Risorgimento N`4, 40136 Bologna, Italy \\ Fax +39(051)2093654; E-mail: dap@chem.gu.se,rph@alu.ua.es \\ b Dpto. de Quimica Organica, Universidad de Sevilla, Apdo. de Correos 553, 41071 Seville, Spain \\ c Instituto de Investigaciones Quimicas (CSIC-Use), Isla de la Cartuja, Americo Vespucio s/n, 41092 Seville, Spain \\ Received 2 November 2005
}

\begin{abstract}
Using thioureas as H-bonding organocatalysts, nitroalkenes can be activated for the conjugate addition of hydrazones as neutral nucleophiles. Formaldehyde derivatives react at the azomethine carbon as expected, whereas hydrazones from enolizable aldehydes behave as ene-hydrazines and react at the $\alpha$-carbon instead. Ionic liquids were found to decrease the reaction times considerably compared to commonly used solvents, whereas alternative activation by Lewis acids resulted in decomposition of reactants.
\end{abstract}

Key words: catalysis, ionic liquids, hydrazones, nucleophiles, addition reactions

The usefulness of $N, N$-dialkylhydrazones in organic synthesis has been reported for a number of carbon-carbon bond-forming reactions. ${ }^{1}$ Being considered as aza-enamines, they have been used as nucleophiles with the addition occurring at the azomethine carbon. The fundamental work of Brehme and co-workers has shown that the addition takes place with strong electrophiles such as tosyl isocyanates, tosyl amides and the Vilsmeier-Haack reagent. ${ }^{2}$ In more recent times, formaldehyde $N, N$-dialkylhydrazones have been used as synthetic equivalents of the formyl and cyanide anions, ${ }^{3}$ for example in the conjugate addition to conjugated nitroalkenes. ${ }^{4}$ There are also examples of asymmetric additions to several types of carbonyl compounds, ${ }^{5} \quad \alpha, \beta$-unsaturated lactones, ${ }^{6}$ alkylidene malonates ${ }^{7}$ and cyclic analogues, ${ }^{8}$ conjugated enones, ${ }^{9}$ and nitroalkenes ${ }^{10}$ using proline-derived formaldehyde hydrazones. Recently an organocatalytic addition of a formaldehyde hydrazone to imines has been reported. ${ }^{11}$ However, reports on the use of hydrazones from other aldehydes have been sparse due to their inherent lower reactivity. ${ }^{2}$

Lately, ureas and thioureas have gained attention as $\mathrm{H}$ bond donors for a number of organo-catalyzed transformations. ${ }^{12}$ The easily available double hydrogen-bonding motif has become a powerful tool for the activation of e.g., carbonyl and nitro compounds. Among the different structures thiourea 1, reported by Schreiner and Wittkopp, ${ }^{13}$ has proved to be useful for the activation of

SYNLETT 2006, No. 2, pp 0239-0242

Advanced online publication: 23.12.2005

DOI: 10.1055/s-2005-922791; Art ID: G36005ST

(C) Georg Thieme Verlag Stuttgart · New York nitroalkenes, for example in the Friedel-Crafts alkylation (Figure 1). ${ }^{14}$

On this basis, we reasoned that the use of organocatalyst 1 could raise the level of reactivity of substrates such as nitroalkenes to the point required for the conjugate addition of relatively unreactive hydrazones, as those derived from simple aldehydes other than formaldehyde.<smiles>FC(F)(F)c1cc(NC(=S)Nc2cc(C(F)(F)F)cc(C(F)(F)F)c2)cc(C(F)(F)F)c1</smiles>

Figure 1

Thus, studies using hydrazones $\mathbf{2 a - f}$ in the conjugate addition to nitrostyrene (3a) were initiated and the results are summarized in Table $1 .{ }^{15}$

In line with earlier reports, ${ }^{4}$ the uncatalyzed addition of formaldehyde hydrazone 2a to $\beta$-nitrostyrene (3a) proceeded to yield $\mathbf{4 a a}$ as product with incomplete conversion after 18 hours. On the other hand, using thiourea 1 (20 $\mathrm{mol} \%$ ) as the catalyst resulted in full conversion of nitrostyrene (3a), leading to the isolation of $\mathbf{4 a a}$ in $90 \%$ yield after the same reaction time (Table 1, entry 1 ).

Moving to enolizable hydrazones $\mathbf{2 b - e}$, only negligible disappearance of the starting material was observed in the uncatalyzed reaction, even after prolonged reaction times. In sharp contrast, the presence of $\mathbf{1}$ as catalyst led to extensive consumption of nitrostyrene (3a) at reasonable rates (Table 1, entries 2-5). However, we did not observe any formation of the expected product, resulting from nucleophilic attack of the hydrazone at the azo-methine carbon. Instead the products were identified as $\mathbf{4 b a - f a}$ indicating that the nucleophilic attack had taken place at the $\alpha$-position of the hydrazone rather than at the azomethine carbon. To the best of our knowledge, the nucleophilic reactivity of the $\alpha$-carbon of hydrazones under nonbasic conditions is totally unprecedented. Assuming that the hydrazone must be in equilibrium with its ene-hydrazine form, a mechanistic proposal for the observed reactivity is shown in Scheme 1. 
Table 1 Reaction of Hydrazones 2a-f with $\beta$-Nitrostyrene (3a) Using Catalyst $\mathbf{1}^{15}$
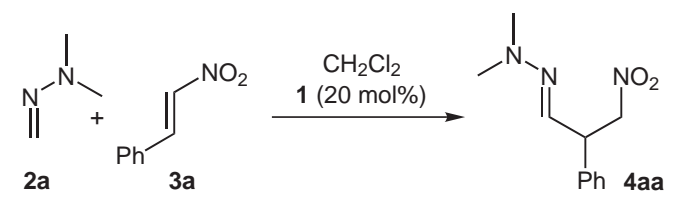

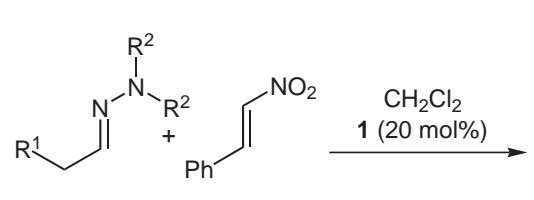

$3 a$

2b $R^{1}=H, R^{2}=M e$

2c $R^{1}=M e, R^{2}=M e$

2d $R^{1}=P h, R^{2}=M e$

$2 e R^{1}=M e, R^{2}=-\left(\mathrm{CH}_{2}\right)_{4}-$

2f $R^{1}=M e, R^{2}=P h$

\begin{tabular}{llclll}
\hline Entry & Hydrazone & Time (h) & Product & $\mathrm{dr}^{\mathrm{a}}$ & ${\text { Yield }(\%)^{\mathrm{b}}}^{\mathrm{a}}$ \\
\hline 1 & $\mathbf{2 a}$ & 18 & $\mathbf{4 a a}$ & - & $90(61)$ \\
2 & $\mathbf{2 b}$ & 140 & $\mathbf{4 b a}$ & - & $58(17)$ \\
3 & $\mathbf{2 c}$ & 21 & $\mathbf{4 c a}$ & $7: 1$ & $77(3)$ \\
4 & $\mathbf{2 d}$ & 24 & $\mathbf{4 d a}$ & $5: 1$ & $92(0)$ \\
5 & $\mathbf{2 e}$ & 8 & $\mathbf{4 e a}$ & $6: 1$ & $73(11)$ \\
6 & $\mathbf{2 f}$ & 24 & $\mathbf{4 f a}$ & - & $0(0)$ \\
\hline
\end{tabular}

${ }^{\text {a }}$ Diastereomeric ratio determined by ${ }^{1} \mathrm{H}$ NMR on the crude product. ${ }^{b}$ Isolated yields after column chromatography. In parenthesis conversions of nitrostyrene for the corresponding uncatalyzed reactions (determined by ${ }^{1} \mathrm{H}$ NMR on the reaction mixtures).

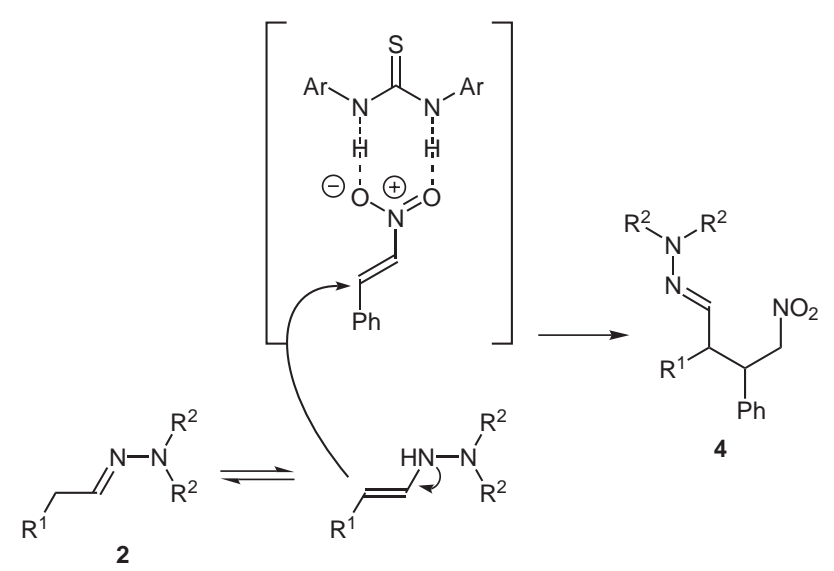

Scheme 1 A proposed explanation for the catalytic effect and the observed reactivity

The products $\mathbf{4}$ contain two adjacent stereogenic centers and were obtained as mixture of diastereoisomers. Fortunately the products could be separated by column chromatography to obtain the pure major stereoisomers. A sizeable effect on the reactivity in the presence of organocatalyst 1 was noticed after changing the alkyl chain bound to the azo-methine carbon. Thus, a rather long reaction time $(140 \mathrm{~h})$ was needed for full conversion using acetaldehyde derived hydrazone $\mathbf{2 b}$ under catalyzed conditions (entry 2), while hydrazone $\mathbf{2 c}$ and $\mathbf{2 d}$ reacted smoothly in 24 hours (entries 3 and 4). These results can be rationalized by considering the stability of the ene-hydrazine forms of the hydrazones, the less substituted acetaldehyde derived ene-hydrazine being rather unstable as compared to the more substituted or conjugated ene-hydrazines of 2c and 2d. The hydrazone originated from isobutyraldehyde was found to be unreactive, a fact attributed to the steric hindrance of the bulky isopropyl group at the reacting center in the corresponding ene-hydrazine.

In order to check if the reaction at the azomethine carbon could be forced, we decided to investigate the behavior of hydrazones not bearing hydrogens at the $\alpha$-carbon, which, therefore, cannot react as ene-hydrazines. However, no reaction was observed with benzaldehyde or pivalaldehyde $\mathrm{N}, \mathrm{N}$-dimethylhydrazones using nitrostyrene (3a) as substrate and catalyst $1 .^{16} \mathrm{Next}$, the effect of different substitution patterns at the amino nitrogen was also investigated. Interestingly, hydrazone 2e derived from $\mathrm{N}$ aminopyrrolidine showed increased reactivity compared to $2 \mathbf{c}^{17}$ (entries 3 and 5). On the other hand the N,N-diphenylhydrazone (2f), being bulkier and with a poorer electron-donating amino moiety, was not reactive in this conjugate addition (Table 1, entry 6).

This initial screening was carried out using dichloromethane with a catalyst loading of $20 \mathrm{~mol} \%$. Other solvents such as toluene and chloroform gave similar outcomes whereas $\mathrm{THF}, \mathrm{MeOH}$ or $\mathrm{MeCN}$ gave poorer results. However, we found that use of ionic liquids $\left(\mathrm{BMImBF}_{4}\right.$ or $\left.\mathrm{BMImPF}_{6}\right)$ accelerated the uncatalyzed reactions compared to other solvents. ${ }^{18}$ For example, the addition of hydrazone $2 \mathbf{c}$ to nitrostyrene (3a) resulted in full disappearance of nitrostyrene in 24 hours, which is similar to the results obtained in the catalytic reaction in dichloromethane. However, products $\mathbf{4}$ were obtained in generally much lower yields (30-50\%) for reactions in ionic liquids. Unfortunately, the combination of an ionic liquid with catalyst $\mathbf{1}$ was unsuccessful.

The generality of this conjugate addition was demonstrated by performing reactions between a variety of aliphatic

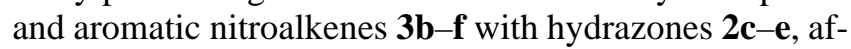
fording good-to-excellent yields of the expected adducts in all cases (Table 2).

The results collected in Table 1 and Table 2 clearly demonstrate that catalyst $\mathbf{1}$ accelerates the conjugate addition. ${ }^{19}$ In contrast, use of catalytic amounts of Lewis acids, such as $\mathrm{Sc}(\mathrm{OTf})_{3}, \mathrm{In}(\mathrm{OTf})_{3}, \mathrm{InF}_{3}$ or $\mathrm{Cu}(\mathrm{OTf})_{2}$, results in no or little product formation accompanied by decomposition of the starting material in the addition of hydrazone 2c to nitrostyrene (3a) after 24 hours. These findings indicate that use of thiourea-based organocatalysts is the key strategy for this reaction, since it provides a useful protocol for the conjugate addition of hydrazones to nitroalkenes. Due to their versatile functional group trans- 
Table 2 Reaction of Nitroalkenes (3b-f) with Hydrazones Catalyzed by $\mathbf{1}^{15}$

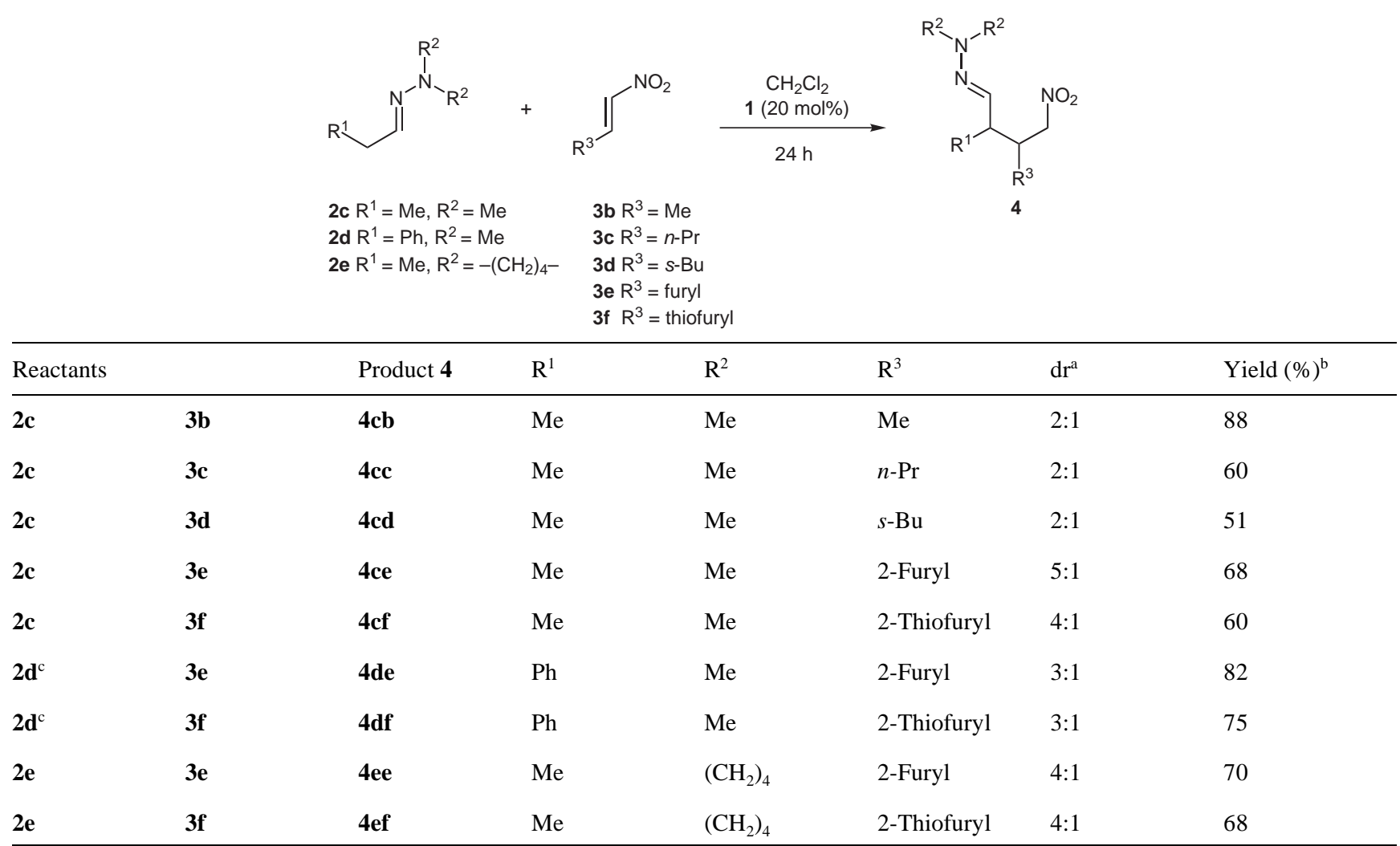

${ }^{\mathrm{a}}$ Diastereomeric ratio determined by ${ }^{1} \mathrm{H}$ NMR on the crude product.

${ }^{b}$ Isolated yields after column chromatography.

${ }^{\mathrm{c}}$ Reaction time $40 \mathrm{~h}$.

formations, the obtained functionalized nitro-derivatives can be considered important intermediates in organic synthesis. $^{20}$

In summary we have provided a broadened scope for the organocatalytic conjugate addition of hydrazones to nitroalkenes. Using catalyst $\mathbf{1}$, enolizable hydrazones behave as ene-hydrazines, reacting at the $\beta$-position to afford $\gamma$-nitrohydrazones in good yields. The scope and limitations of the methodology, as well as the development of a stereoselective version based on chiral $\mathrm{H}$-bonding catalysts, are current objects of study in our laboratories.

\section{Acknowledgment}

We gratefully acknowledge financial support by the National Project 'Stereoselezione in Sintesi Organica. Metodologie ed Applicazioni, 2003', by the RTN project 'Design, Analysis and Computation for Catalytic Organic Reactions', contract HPRN-CT2001-00172, and by the ex-60\% MURST-funds 2004.

\section{References and Notes}

(1) (a) Kamitori, Y.; Hojo, M.; Masuda, R.; Fujitani, T.; Ohara, S.; Yokoyama, T. J. Org. Chem. 1988, 53, 129.

(b) Kamitori, Y.; Hojo, M.; Masuda, R.; Yoshida, T.; Ohara, S.; Yamada, K.; Yoshikawa, N. J. Org. Chem. 1988, 53, 519.
(2) (a) Brehme, R.; Nikolajewski, H. E. Tetrahedron 1969, 25, 1159. (b) Brehme, R.; Nikolajewski, H. E. Tetrahedron Lett. 1982, 23, 1131. (c) Brehme, R.; Reck, G.; Schulz, B.; Redeglia, R. Synthesis 2003, 1620.

(3) Lassaletta, J. M.; Fernández, R. Synlett 2000, 1228.

(4) Lassaletta, J. M.; Fernández, R.; Gasch, C.; Vázquez, J. Tetrahedron 1996, 52, 9143; and references therein.

(5) (a) Fernández, R.; Martín-Zamora, E.; Pareja, C.; Lassaletta, J. M. J. Org. Chem. 2001, 66, 5201. (b) Fernández, R.; Martín-Zamora, E.; Pareja, C.; Vázquez, J.; Díez, E.; Monge, A.; Lassaletta, J. M. Angew. Chem. Int. Ed. 1998, 37, 3428.

(6) Enders, D.; Vázquez, J.; Raabe, G. Eur. J. Org. Chem. 2000, $6,893$.

(7) (a) Vázquez, J.; Prieto, A.; Fernández, R.; Enders, D.; Lassaletta, J. M. Chem. Commun. 2002, 498. (b) Lassaletta, J. M.; Vázquez, J.; Prieto, A.; Fernández, R.; Raabe, G.; Enders, D. J. Org. Chem. 2003, 68, 2698.

(8) Vázquez, J.; Cristea, E.; Díez, E.; Lassaletta, J. M.; Prieto, A.; Fernández, R. Tetrahedron 2005, 61, 4115.

(9) (a) Lassaletta, J. M.; Fernández, R.; Martín-Zamora, E.; Díez, E. J. Am. Chem. Soc. 1996, 118, 7002. (b) Díez, E.; Fernández, R.; Gasch, C.; Lassaletta, J. M.; Llera, J. M.; Martín-Zamora, E.; Vázquez, J. J. Org. Chem. 1997, 62, 5144.

(10) (a) Fernández, R.; Gasch, C.; Lassaletta, J. M.; Llera, J.-M.; Vázquez, J. Tetrahedron Lett. 1993, 34, 141. (b) Enders, D.; Syrig, R.; Raabe, G.; Fernández, R.; Gasch, C.; Lassaletta, J. M.; Llera, J. M. Synthesis 1996, 48.

(11) Dixon, D. J.; Tillman, A. L. Synlett 2005, 2635. 
(12) (a) Pihko, P. M. Angew. Chem. Int. Ed. 2004, 43, 2062. (b) Sigman, M. S.; Jacobsen, E. N. J. Am. Chem. Soc. 1998, 120, 4901

(13) (a) Schreiner, P. R.; Wittkopp, A. Org. Lett. 2002, 4, 217. (b) Wittkopp, A.; Schreiner, P. R. Chem.-Eur. J. 2003, 9, 407.

(14) (a) Dessole, G.; Herrera, R. P.; Ricci, A. Synlett 2004, 2374. (b) Herrera, R. P.; Sgarzani, V.; Bernardi, L.; Ricci, A. Angew. Chem. Int. Ed. 2005, 44, 6576.

(15) Experimental Procedure.

To a mixture of thiourea $1(0.02 \mathrm{mmol}, 10 \mathrm{mg})$ and nitroalkene $(0.1 \mathrm{mmol})$ in $\mathrm{CH}_{2} \mathrm{Cl}_{2}(100 \mu \mathrm{L})$ was added hydrazone $(0.15 \mathrm{mmol})$. The reaction was then stirred for the time stated at ambient temperature. The product was isolated as an oil using column chromatography (EtOAc-hexane, 1:4). All compounds gave satisfactory analytical and spectral data.

Typical data for representative compounds: Compound 4ca (19.2 mg, 77\%): Major diastereomer: ${ }^{1} \mathrm{H}$ NMR (300 MHz, $\left.\mathrm{CDCl}_{3}\right): \delta=0.85(3 \mathrm{H}, \mathrm{d}, J=6.87 \mathrm{~Hz}$, $\left.\mathrm{CH}_{3}\right), 2.62\left(1 \mathrm{H}, \mathrm{m}, J=6.87,7.11,10.2 \mathrm{~Hz}, \mathrm{CH}_{3} \mathrm{CH}\right), 2.75$ [6 H, s, N( $\left.\left(\mathrm{CH}_{3}\right)_{2}\right], 3.41(1 \mathrm{H}$, dt-like, $J=5.27,10.20 \mathrm{PhCH})$, $4.53\left(1 \mathrm{H}, \mathrm{dd}, J=9.87,12.9 \mathrm{~Hz}, \mathrm{C} H \mathrm{NO}_{2}\right), 4.76(1 \mathrm{H}, \mathrm{dd}$, $\left.J=5.07,12.9 \mathrm{~Hz}, \mathrm{CHNO}_{2}\right), 6.39(1 \mathrm{H}, \mathrm{d}, J=7.11, H \mathrm{C}=\mathrm{N})$, 7.08-7.37 (5 H, m, Ph). ${ }^{13} \mathrm{C}$ NMR (75 MHz, $\left.\mathrm{CDCl}_{3}\right)$ : $\delta=17.96,41.14,43.18,48.79,79.94,127.9,128.3,129.1$, 136.7, 138.7. ESI-MS: $m / z=272\left[\mathrm{M}+\mathrm{Na}^{+}\right]$. HRMS: $m / z$ calcd for $\mathrm{C}_{13} \mathrm{H}_{19} \mathrm{~N}_{3} \mathrm{O}_{2}: 249.1477$; found: 249.1475 .

Compound 4de (24.7 mg, 82\%): Major diastereomer: ${ }^{1} \mathrm{H}$ $\operatorname{NMR}\left(300 \mathrm{MHz}, \mathrm{CDCl}_{3}\right): \delta=2.80\left[6 \mathrm{H}, \mathrm{s}, \mathrm{N}\left(\mathrm{CH}_{3}\right)_{2}\right], 3.89$ $(1 \mathrm{H}, \mathrm{dd}, J=5.84,10.3 \mathrm{~Hz}, \mathrm{PhCH}), 4.26(1 \mathrm{H}, \mathrm{m}, \mathrm{CH}), 4.77$ $\left(1 \mathrm{H}, \mathrm{dd}, J=8.96,12.9, \mathrm{CHNO}_{2}\right), 4.95(1 \mathrm{H}, \mathrm{dd}, J=5.01$, 12.9, $\left.\mathrm{CHNO}_{2}\right), 5.83(1 \mathrm{H}, \mathrm{m}$, furyl $), 6.08(1 \mathrm{H}, \mathrm{m}$, furyl $), 6.62$ $(1 \mathrm{H}, \mathrm{d}, J=5.84 \mathrm{~Hz}, H \mathrm{C}=\mathrm{N}), 7.05-7.38(5 \mathrm{H}, \mathrm{m}, P h$ and $1 \mathrm{H}$, furyl). ${ }^{13} \mathrm{C} \mathrm{NMR}\left(75 \mathrm{MHz}, \mathrm{CDCl}_{3}\right): \delta=41.99,43.11,51.07$, 77.25, 108.8, 110.3, 127.2, 128.3, 128.4, 129.3, 139.6, 142.1, 151.2. ESI-MS: $\mathrm{m} / \mathrm{z}=324\left[\mathrm{M}+\mathrm{Na}^{+}\right]$. HRMS: $\mathrm{m} / \mathrm{z}$ calcd for $\mathrm{C}_{16} \mathrm{H}_{19} \mathrm{~N}_{3} \mathrm{O}_{3}$ : 301.1426; found: 301.1424 .

(16) Formation of adducts derived from attack by the azomethine carbon was not observed for any of the studied hydrazones $\mathbf{2 b}-\mathbf{f}$.

(17) Lassaletta, J. M.; Fernández, R.; Martín-Zamora, E.; Pareja, C. Tetrahedron Lett. 1996, 37, 5787.

(18) Yadav, J. S.; Reddy, B. V. S.; Basak, A. K.; Narsaiah, A. V. Tetrahedron Lett. 2003, 44, 2217.

(19) Other H-bonding catalysts such as tartaric acid or mandelic acid were unsuccessfully tried. Furthermore, no decomposition of hydrazones or nitroalkenes in presence of thiourea 1 was observed after one week in $\mathrm{CH}_{2} \mathrm{Cl}_{2}$.

(20) Fujim, K.; Node, M. Synlett 1991, 603. 